\title{
A NATUREZA DO PODER E AS ILUSÕES DO CONTRATO SOCIAL EM ROBERT FILMER
}

\author{
Luiz Felipe Netto de Andrade e Silva Sahd \\ Universidade Federal de Uberlândia \\ felipesahd@yahoo.com.br
}

\begin{abstract}
Resumo: $O$ presente artigo procura mostrar a crítica conservadora inglesa do século XVII às noções de liberdade natural e contrato originário, ao deslocar a origem do poder político para as relações afetivas estabelecidas pelos laços sentimentais de família que mantêm pais e filhos unidos. Mais exatamente, a legitimação politica do poder teria como fundamento uma autoridade natural semelhante à relação verificada entre pais e filhos. Segundo essa teoria, cujo mais importante representante foi Robert Filmer, o fundamento da autoridade política não é fruto de uma instituição arbitrária dos homens, mas uma necessidade introduzida por Deus, com o propósito de justificar as monarquias absolutistas.
\end{abstract}

Palavras-chave: Monarquia, liberdade natural, contrato originário, comunidade.

As teses políticas de Sir Robert Filmer (1588-1653) não são desenvolvidas no quadro de um sistema filosófico dedutivo, mas constituem um comentário crítico que se opõe à teoria política acusada de ser particularmente nova. O seu método evoca um trabalho constante de "erosão" (Dunn, 1969, p. 68), ao descrever as conseqüências do pensamento contratualista sob uma ótica muito particular, a saber: ele zomba da ausência de continuidade entre as conseqüências do pacto social e os pressupostos de ordem social existentes. Consideradas um comentário, as teses de Filmer são tão coerentes em sua argumentação e apresentam um estilo igualmente repetitivo quanto as teses defendidas pelo seu principal acusador, John Locke. ${ }^{1}$ Os diversos escritos de Filmer, porém, não constituem um corpo de doutrina politica. Uma idéia, no entanto, é dominante: o poder real deriva do poder paterno. Para justificar essa tese principal, Filmer sustenta que a origem da sociedade humana 
remonta a Adão e que as relações que se estabelecem na sociedade política, entre governantes e governados, derivam da autoridade paterna. Os dois argumentos permitem não só considerar a tese segundo a qual a sociedade é uma grande família e Adão o seu único tronco, mas também recusar todo pretenso direito de sedição enraizado numa liberdade originária do povo. ${ }^{2}$ A tese - o poder real deriva do poder paterno -, de fato, não é nova. Se as informações de Peter Laslett estão corretas, em 1640, quando Filmer compõe o Patriarcha, essa idéia é quase banal, ela é freqüentemente associada à teoria do direito divino dos reis, doutrina oficial da Igreja Católica Romana. Há, porém, uma diferença importante que marca a originalidade de Filmer, a saber: o autor não identifica as duas teses, mas insiste sobre uma concepção patriarcal e patrimonial do poder dos reis.

Qual é a principal intenção da obra de Robert Filmer? Estabelecer a legitimidade da autoridade do rei sobre os seus súditos, negando a existência de um compromisso ou pacto mútuo que limite o seu poder, impondo-lhe restrições. E qual é o argumento central dessa tese? A autoridade real é natural. ${ }^{3} \mathrm{O}$ seu fundamento não é fruto de uma instituição arbitrária dos homens, mas, sim, uma necessidade introduzida pelo Criador, quando formou a própria natureza em que estão inseridos e fazem parte. O que justifica tal premissa? Os homens são naturalmente desiguais e submetidos a um outro. $\mathrm{O}$ exemplo dessa relação seletiva encontra-se na própria criança quando nasce, ela é submissa ao seu pai que a engendrou, não sendo independente e livre, mas permanecendo sob sua tutela. Essa dependência, porém, é anterior a toda convenção, é uma subordinação natural das crianças à autoridade de seus parentes, que recebem da própria natureza um poder absoluto sobre os seus filhos. A dominação política, por sua vez, é apenas a conseqüência lógica dessa desigualdade fundamental, ou seja, é a extensão da autoridade dos pais sobre suas crianças. Há uma transformação dela em autoridade soberana, fazendo do rei, pai de família, o chefe de seu povo. Em outras palavras, Deus, ao criar a natureza, criou 
também a autoridade do pai sobre as crianças e, por conseguinte, do rei sobre os seus súditos

Pode parecer absurdo manter que atualmente os reis são os pais de seu povo, visto que a experiência mostra o contrário. É verdade que os reis não são os pais naturais dos súditos, mas são todos eles, ou devem ser considerados, os mais próximos sucessores dos primeiros progenitores que foram no princípio os pais naturais de todo o povo, e os herdeiros de seus direitos ao exercício da suprema jurisdição; e estes herdeiros são não só senhores de seus próprios filhos, senão também de seus irmãos e de todos os demais que estavam sujeitos aos seus pais. (FILMER, 1991, p. 10)

Notamos, aqui, duas espécies de prova da extensão do poder paterno ao poder absoluto do rei. Uma histórica, em que o autor inglês sustenta que, no começo, os reis foram os pais naturais dos súditos; e outra simbólica, em que ele declara com firmeza que eles também devem ser reputados os herdeiros dos primeiros pais. Esse título de Pater Patriae para o monarca é reforçado com o seguinte desenvolvimento do argumento: com o tempo, as primeiras gerações desaparecem, extinguindo-se a verdadeira paternidade, ficando apenas o direito do legítimo herdeiro. Entretanto, somente ao rei cabe reivindicar a herança à paternidade deixada por seus antepassados, que a possuíam por natureza, a ninguém mais, nem mesmo ao povo para quem a maior liberdade é viver submetido ao monarca (Filmer, 1991, p. 5). A teoria de Filmer recusa ao povo a possibilidade de deter a soberania política da nação; esta não lhe diz respeito, nem lógica nem historicamente. Isso acontece mesmo quando se desconhece o possível herdeiro ao trono, visto que o reino é composto da união das grandes famílias ou pequenos reinos, cabendo somente aos príncipes e aos chefes das famílias independentes o poder real vacante, não ao povo.

Assim sendo, o direito paterno de autoridade soberana não é uma concessão do povo, mas uma delegação de Deus, que outorga 
ao monarca o caráter real de pai universal. E essa delegação de poder, segundo Filmer (1991, p. 11), pode ser concedida por um príncipe. $\mathrm{O}$ monarca deve obediência unicamente ao Criador, pois está ao mesmo tempo acima das leis e dos homens e é o seu digno representante na Terra. Contudo, em seus desígnios secretos, se Deus consente na destituição de um príncipe, seja através de uma conspiração da nobreza, seja através de uma rebelião popular, Ele o faz sempre com justiça: "Deus somente utiliza e dirige os atos injustos (Unrighteous Acts) dos homens para o cumprimento de seus justos decretos (Righteous Decrees)" (FILMER, 1991, p. 11). Ele tem o poder de dar e retirar os reinos, todavia aquele que agir sem a sua autorização pratica uma ação pecaminosa e condenável, infringe as suas leis e faz uso indevido de seus juízos. Em suma, o essencial da perspectiva levantada no Patriarcha está no fato de que todo fundamento da autoridade política reside no direito natural da autoridade do pai supremo. "Existe e existirá até o fim do mundo o direito natural de um pai supremo sobre toda multidão" (FILMER, 1991, p. 11). A confirmação do raciocínio encontra-se na conhecida lei que ordena obediência ao soberano nos moldes do Honour thy Father (Honrarás a teu pai). Nem a objeção sobre a imediata aplicação da lei natural, em se tratando da relação do pai com seu filho, é mediata, através de um mandato humano, de sujeição destes ao príncipe, nem evidentemente a indagação sobre qual a razão que permitiria a lei natural transferir suas prerrogativas às leis dos homens abalaram a convicção do autor. A sua resposta identificou o direito natural do pai com o do rei, ambos, para Filmer (1991, p. 12), são a mesma coisa: "Como o pai sobre uma família, também o rei estende sua solicitude sobre muitas famílias para preservar, alimentar, vestir, instruir e defender a toda a comunidade (Commonwealth)". Há uma extensão entre o poder paterno e o poder do monarca, tanto nas suas obrigações de rei/pai para com seus súditos/filhos como para os sentimentos afetivos típicos da relação paternal. A defesa do reino visa preservar a integridade dos pais de família de "nível inferior" e de seus descendentes, como se a relação 
política entre as pessoas de uma determinada nação não ultrapassasse as relações pessoais no âmbito comunitário. A frase que encerra o primeiro capítulo do Patriarcha não deixa nenhuma dúvida sobre o assunto. Os deveres do rei para com seu povo são semelhantes a uma espécie de Universal Fatherly Care, um sentimento universal e fraterno pelos membros de sua comunidade.

Contudo, algumas considerações são necessárias para tentar um esclarecimento de questões importantes que freqüentam a discussão sobre a teoria patriarcal de Filmer - e como o autor do condado de Kent rejeita -, ao oferecer uma resposta polêmica e em conformidade com a doutrina dos imperadores nas lutas contra o Pontificado, a perspectiva do cardeal Belarmino sobre a origem do poder político. Ao contrário do que pensava o cardeal, Deus não outorgou ao povo - nem mesmo à humanidade - a autoridade soberana, não fazendo dele o seu depositário na Terra, mas investiu um homem particular, Adão, por um direito de paternidade, do poder real absoluto que, entre outras coisas, tem o inteiro domínio sobre as suas crianças (FILmer, 1991, p. 7). A própria criação do primeiro homem reforça essa doutrina: a sua constituição se deu a partir de uma origem unitária, um indivíduo chamado Adão, e não de uma multiplicidade de vontades particulares, ou mesmo do par homem-mulher, que testemunharia a fragmentação do poder em várias partes, exigindo um consensus geral, em se tratando da sua transmissão a um ou vários representantes da vontade soberana. A mulher criada do homem ressalta a tese acima, pois estabelece uma cadeia hierarquizada de subordinações. $O$ pai detém a chefia da família, e os filhos, o mando de suas futuras crianças. A supremacia do primogênito, segundo Filmer (1991, p. 9-10), completa o quadro proposto, isto é, Deus cedeu a Caim o domínio sobre o seu irmão Abel, e assim sucessivamente até os dias de hoje (pleno reinado de Carlos I) como uma cadeia necessária que não aceita interrupções, salvo algumas exceções. A família, para Filmer, é o germe da sociedade civil. Nesse sentido, a origem do poder político está nessa subordinação das crianças - que, ao longo da história, 
descendem de Adão - aos seus legítimos herdeiros, os patriarcas do futuro. Do mesmo modo, esse poder absoluto e ilimitado do pai tem a força para dispor como desejar a vida e a morte de seus filhos e dos seus súditos: está escrito nas Escrituras que eles "eram uma só coisa no começo", bens pertencentes ao Senhor, objetos de seu usufruto. Não há nenhuma restrição de qualquer ordem para o seu uso (FILMER, 1991, p. 7). ${ }^{4}$

Como um modelo retirado de Deus - Deus é Pai -, o poder paterno e monárquico que se encontra na origem da humanidade não se perde jamais. A sua permanência está garantida durante todo o tempo em que existir o mundo dos homens com suas relações de força e mando; apenas a nossa consciência pode perdê-la como um elemento constitutivo da convivência política, porque sempre haverá, segundo Filmer (1991, p. 11), "um direito natural de um Pai supremo sobre uma multidão”. Não importa nem mesmo o modo como esse exercício real da soberania é obtido; seja ele por uma eleição, seja ele por uma usurpação, o sentido permanece o mesmo: há sempre um herdeiro legítimo, ainda que não possamos saber quem ele é. O usurpador é o melhor exemplo da obrigação dos súditos para com um rei legítimo e senhor da sua supremacia, pois Deus autoriza a troca de príncipes genuínos por outros, como forma de correção do soberano, ou mesmo como um modo de punição dos povos. ${ }^{5}$ A vontade de Deus é sempre justa, apesar da ação pecaminosa dos homens que os tornam figuras abjetas, concupiscentes, merecedoras de repúdio e condenação. Contudo, o primeiro usurpador deve ser visto pelos súditos apenas como um agente que irá concluir a vontade de seu superior, ao receber um dever e um direito condicional de governabilidade; o usurpador deve transformar-se aos olhos dos usurpados no verdadeiro herdeiro do trono.

Dois traços essenciais, por fim, unem-se à tese do poder patriarcal, caracterizando a primazia do rei sobre os seus comandados. São eles: o caráter natural da monarquia e a identidade do poder político e do poder econômico. O tema específico do caráter natural da monarquia, como uma forma de governo, percorre todas as obras 
de Filmer (CARrive, 1984, p. 72), e não é sem razão que o autor insiste nesse argumento; através dele a justificação dos outros tipos de governos que sucedem da conquista, do consentimento ou do contrato firmado pelos súditos de um determinado Estado, não é razoável e plausível. Os seus defensores, segundo Filmer, baseiam os seus argumentos num frágil arcabouço teórico. ${ }^{6}$ Duas idéias asseguram à monarquia a sua prioridade sobre a aristocracia e a democracia como modelo ideal e perfeito. Deus a tornou natural por sua própria vontade, ele quis que assim fosse, e, como conseqüência direta, ele escolheu a monarquia como a forma legítima e natural de governo. ${ }^{7}$ Retomando uma citação de João Crisóstomo feita por Suarez, Filmer (1991, p. 14) demonstra que na criação Deus dá prova da sua preferência pela monarquia: "Deus fez toda a humanidade a partir de um único homem, para poder ensinar ao mundo como ser governado por um rei e não por uma multidão". Novamente o testemunho de Adão é suficiente para fundamentar o poder monárquico, pois Deus ordenou a instituição da autoridade real sobre os homens ao rejeitar outros modos de poder que não encontram semelhante ordenação divina para justificá-los. Além disso, um outro argumento corrobora a argüição de Filmer, o caráter paterno do rei, que o submete à lei natural do pai, investindo-o de um poder sobre o seu povo, com a intenção de fazer cumprir os atos bons de seus ancestrais. Certamente um argumento diferente, porém ele alcança os mesmos objetivos que perpetuam o poder real, isto é, a sua inesgotável dominação, cujos propósitos recusam absolutamente as teorias defensoras do tiranicídio como uma ação legítima na política. $O$ poder do príncipe não cessa naturalmente como pensam alguns, porque, se isso acontecesse, seria o mesmo que alegar a sua origem arbitrária, criada por uma convenção humana, permitindo assim a existência de pactos e contratos sociais. Nada mais contrário à perspectiva do autor inglês, vindo abaixo o principal argumento de sua doutrina política. Se julgar as ações de um rei é agir de forma desnaturada, o que será destituí-lo de seu cargo? Seria provocar, segundo Filmer, o pior dos 
males: a anarquia popular em que impera a falta de autoridade e o fatídico desgoverno que destrói as relações humanas.

A natureza da relação de comando não se restringe, porém, à situação privilegiada do monarca, o súdito também recebe um atributo intrínseco à sua natureza: a obediência absoluta ao superior. Faz parte da essência do homem inferiorizado hierarquicamente estar submetido ao poder de um outro, que o acolhe no seio da grande família que representa a sociedade sob o regime monarquista e exige um respeito incondicional à sua tutela, pois sem ele não existiria a menor possibilidade do convívio racional e pacificado dos homens no corpo político, apenas a balbúrdia, que denotaria as ações individuais de pessoas sagazes, ansiosas do poder sobre tudo e sobre todos. Mais do que um simples complemento à teoria, essa constatação do servilismo inerente à essência do ser humano, um ser que manda ou que obedece pertence à própria estrutura do pensamento político de Filmer, servindo de fundamento para as suas idéias. Ela não pode ser relegada a um segundo plano, principalmente quando o autor inglês diz, de modo inequívoco, que "todo homem é por natureza rei ou súdito" (Filmer, apud CARrive, 1984, p. 73); claro está o que ele pretendia, mas, mais do que isso, o que a própria teoria exigia para se tornar consistente era apresentar um mínimo de coerência na articulação interna de suas noções mais importantes. Fica evidente, assim, o fundamento da doutrina de Filmer, a saber: a defesa irrestrita da inexistência de dois conceitos intimamente ligados, a liberdade natural e a igualdade comum a todos os membros que compõem o povo. Há uma rejeição ao que Carrive (1984, p. 74) chamou de "um mito em duas faces", quando damos uma definição do que é natural para Filmer: o poder do rei e a sujeição do povo. ${ }^{8}$

Esse leit-motiv da obra tem um endereço certo e localizado: denunciar os "terriveis inconvenientes que acompanham a doutrina da liberdade natural” (FiLmer, 1993, p. 3). Enganam-se aqueles que acreditam nessa concepção do poder natural do povo em dispor de seu próprio destino, tomando para si a responsabilidade das ações 
da alçada do soberano, ao ditar as regras do jogo que devem regular o Estado. Fazendo da liberdade natural um elemento básico de suas teorias, esses autores não percebem o óbvio: todo e qualquer poder só pode ser concedido ao povo por um dom ou por uma graça do rei que lhe foi investido naturalmente. Só ele dispõe do poder conforme a sua vontade soberana. Sustentar o contrário seria sucumbir ao erro da ficção do contrato social, como criador do corpo político, um passo obrigatório para se passar do estado de natureza, no qual todos os homens são absolutamente iguais e livres, ao estado civil. ${ }^{9}$ Não há contrato original, eleição, ou mesmo uma escolha, que justifique a tese, segundo a qual todo poder emana do povo. Perversa ilusão que tende a criar uma situação em que os subordinados pensam retirar das suas próprias forças um poder que eles não têm e nunca tiveram, e cujos efeitos são a principal causa das perturbações populares, astutamente fomentadas e muitas vezes conduzidas por pessoas ou partidos sectários contra o poder absoluto do soberano. Um bom exemplo disso, segundo Filmer, está nos limites da atuação do Parlamento inglês, mais exatamente na liberdade facultada pelo rei para o funcionamento das duas casas que o compõem. Contra o argumento dos membros da Câmara dos Comuns, que alegam que os seus poderes são resguardados por princípios naturais, dando liberdade para agirem como quiserem, uma vez que são os legítimos representantes do corpo do reino, Filmer objeta enfaticamente: esses privilégios alcançados pelos parlamentares não dependem exclusivamente deles, mas dos favores que o rei generosamente concedeu, pois a liberdade oriunda da graça real e a originada da natureza - ambas são uma coisa só procedem dos benefícios outorgados pelo monarca. ${ }^{10}$

O segundo traço importante que se une à monarquia, centrada sobre o paternalismo, é a aproximação entre o poder político e o poder econômico, ou seja, a constatação da mesma natureza para ambos os poderes, tornando-os idênticos. A dedução que torna perfeitamente igual a força física e moral do chefe de família e do governante segue a mesma linha de raciocínio da 
analogia apreciada anteriormente entre o governo dos homens e a noção de patrimônio. Para entendê-la corretamente, porém, precisamos tornar clara qual é a sua origem, que concilia num mesmo movimento a formação da comunidade, com suas regras de conduta, e a propriedade privada que, aos olhos de Filmer, não faz parte dos direitos naturais. A resposta não poderia ser diferente: põe em cena outra vez a figura do primeiro homem como causa dos dois poderes: Adão recebeu de Deus um poder natural e privado que está na origem de todo governo e de toda propriedade existente no mundo, após a sua criação. Assim sendo, a propriedade só é uma propriedade privada quando, por um direito pessoal, Adão resolveu transmiti-la segundo a sua conveniência a terceiros, os seus legítimos herdeiros, que passam a ter um direito sobre ela. Se Adão traz em si o princípio da autoridade familiar sobre todas as coisas, a semelhança intrínseca entre a família, com a sua economia doméstica, e a república, uma união de várias famílias sob a jurisdição de um único chefe, o monarca, não pode ser contestada. Em última instância, guardadas as devidas proporções que sugerem uma diferença “acidental de ampliação”, cuja extensão dos limites não é a mesma para as duas, uma é bem maior do que a outra, a analogia entre os dois modos de governar é a verdadeira conclusão a que chega Filmer, em “Observations upon Aristotle's politique”, devendo constituir-se no ponto crucial de seu pensamento político a favor da monarquia absolutista (FILMER, 1991, p. 281).

Algumas considerações finais são necessárias. A importância dos temas é clara: o poder que descende por direito de Adão a seus filhos e a todos os patriarcas é um poder absoluto, monárquico, ilimitado. É um poder de vida, de morte e de castração. Sendo originariamente o poder de um pai, rei e senhor de família, foi transmitido como tal a seus descendentes, de modo que o direito absoluto do patriarca significasse também o direito de dispor das crianças e dos servos. O poder dos reis é um poder natural. E uma vez que a autoridade real é, como a autoridade paterna, uma “instituição natural”, não tem necessidade de ser justificada nem 
pela conquista, nem por um contrato, nem pelo consentimento dos súditos. Deus simplesmente exprime nela, como na criação, "a excelência da monarquia”. Por conseguinte, a obediência dos súditos à autoridade real só pode ser transformada por uma lei de Deus. Em outras palavras, a idéia de liberdade natural não tem sentido para Filmer, e todos aqueles que construíram uma doutrina da liberdade e da igualdade naturais dos homens, como Grotius, Selden e Hobbes, estão expostos a "terríveis inconvenientes". Contra Hobbes, Filmer afirma que, em razão da sua origem e por vontade divina, os homens estão e sempre estiveram submetidos a seus pais, o que significa negar simultaneamente as suas igualdade e liberdade naturais. A relação de mando e obediência que existe entre o pai e os filhos, ou entre o príncipe e os súditos, portanto, implica uma rejeição de ambas, liberdade e igualdade naturais, e propõe apenas a existência da liberdade, em virtude de uma graça especial do rei, expressão direta de suas liberalidade e indulgência. Além disso, a soberania dos reis, patriarcal e natural, é também patrimonial: Adão recebeu o dominium natural e privado das coisas. ${ }^{11}$ Dominium e Imperium são propriedades pessoais suscetíveis de transações, segundo Filmer; podem ambos e do mesmo modo, uma vez que são da mesma natureza, ser deixados, alienados e mesmo usurpados. Eis o que ensina, diz Filmer ao retomar várias passagens, a história do Antigo Testamento: o monarca absoluto é o príncipe perfeito dos tempos modernos. Seu absolutismo é semelhante à onipotência divina.

Em última instância, as idéias de Filmer fizeram dele não apenas um oponente intransigente do direito de resistência, mas igualmente um forte adversário da mixed monarchy e de qualquer forma de parlamentarismo.

THE NATURE OF POWER AND THE ILLUSIONS OF THE SOCIAL CONTRACT IN ROBERT FILMER

Abstract: The present article deals with the XVII century conservative English critic to the notions of natural liberty and originary contract, when considering the origin of political power as based on affective relations among family members. More precisely, the 
legitimation of political power might have, as its fundament, a certain natural authority, similar to that experienced between fathers and sons. According to this theory, whose most conspicuous representative is Robert Filmer, the fundament of political authority is by no means arbitrarily established by men, but a necessity introduced by God himself in order to justify absolute monarchies.

Key words: Monarchy, natural liberty, originary contract, commonwealth.

\section{Notas}

1. Quentin Skinner (1996, p. 616) escreve: "Pode-se dizer que John Locke, nos Dois tratados de governo, formulou a crítica decisiva a essas duas tradições, modificando a teoria absolutista de Pufendorf sobre o contrato social e refutando o patriarcalismo de Filmer.

2. Aqui, Robert Filmer parece ter em mente as teses de Buchanan e de Parson sobre o direito dos povos em depor seus príncipes.

3. Mesmo não sendo o traço mais importante do pensamento de Filmer, a teoria patriarcal assume um papel importante nesta argumentação. Cf. Carrive (1984).

4. Cf. Spitz (2001, p. 113-153).

5. Para Carrive (1984, p. 72), Filmer precisa "dar conta da usurpação para tornar sua teoria possível”.

6. Cf. Terrel (2001, p. 235-242).

7. Filmer (1991, p. 23) chega a dizer: "Deus nos ensinou mediante o instinto natural, assinalando na Criação e confirmando, por seu exemplo, a excelência da monarquia”.

8. Franck Lessay ressalta que a monarquia paterna e a sujeição nativa são dois conceitos-chave, além de correlatos, para o pensamento político de Filmer (Filmer, Hobbes, Locke: les cassures dans l'espace de la théorie politique. In: Archives de Philosophie, v. 55, 1992, p. 648).

9. Para uma explicação detalhada da crítica da idéia de contrato diretamente ligada à refutação da tese da liberdade natural do povo, cf. Carrive (1984, p. 76-84). 
10. "A liberdade de expressão, a [liberdade] que a Câmara dos Comuns tem para punir seus membros, a de examinar os atos e as faltas das cortes de justiça e dos empregados do Estado, como ter acesso à pessoa do rei, 'não lhe são devidas por algum direito natural, mas são derivadas da liberdade e da indugência do Rei'” (CARRIVE, 1984, p. 74).

11. Eis aí a raiz teórica dos direitos de propriedade e de governar da política de Robert Filmer.

\section{Referências}

Carrive, P. La pensée politique de Filmer. Cahiers de Philosophie Politique et Juridique de l'Université de Caen, n. 5, p. 61-97, 1984.

Dunn, J. The political thought of John Locke. Cambridge: Cambridge University Press, 1969.

Filmer, R. Patriarcha and other writings. Edited by Johann P. Sommerville. Cambridge: Cambridge University Press, 1991.

Lessay, F. Filmer, Hobbes, Locke: les cassures dans l'espace de la théorie politique. Archives de Philosophie, v. 55, p. 645-659, 1992. Skinner, Q. As fundações do pensamento político moderno. Tradução de Renato Janine Ribeiro e Laura Teixeira Motta. São Paulo: Companhia das Letras, 1996.

SpiTz, J.-F. John Locke et les fondements de la liberté moderne. Paris: PUF, 2001.

Terrel, J. Les théories du pacte social. Paris: Seuil, 2001. 